Article

\title{
Antioxidant Activity of Pastinaca sativa L. ssp. sylvestris [Mill.] Rouy and Camus Essential Oil
}

\author{
Călin Jianu ${ }^{1, *}$, Ionuț Goleț ${ }^{2}$, Daniela Stoin ${ }^{1}$, Ileana Cocan ${ }^{1}$ (D) \\ and Alexandra Teodora Lukinich-Gruia ${ }^{3}$ \\ 1 Faculty of Food Engineering, Banat's University of Agricultural Sciences and Veterinary Medicine "King \\ Michael I of Romania" from Timisoara, Calea Aradului 119, RO-300645 Timisoara, Romania; \\ mucetedaniela@yahoo.com (D.S.); negreaileana@yahoo.com (I.C.) \\ 2 Faculty of Economics and Business Administration, West University of Timisoara, \\ 300233 Timisoara, Romania; ionutgolet@gmail.com \\ 3 OncoGen Centre, County Hospital "Pius Branzeu", Blvd. Liviu Rebreanu 156, \\ RO-300736 Timisoara, Romania; gruia_alexandra@yahoo.com \\ * Correspondence: calin.jianu@gmail.com
}

Received: 20 January 2020; Accepted: 14 February 2020; Published: 16 February 2020

\begin{abstract}
In the last decade, there has been growing interest in the food industry in replacing synthetic chemicals with natural products with bioactive properties. This study's aims were to determine the chemical composition and the antioxidant properties of the essential oil of Pastianica sylvestris. The essential oil was isolated with a yield of $0.41 \%(w / v)$ by steam distillation from the dried seeds and subsequently analysed by GC-MS. Octyl acetate (78.49\%) and octyl hexanoate (6.68\%) were the main components. The essential oil exhibited an excellent activity for the inhibition of primary and secondary oxidation products for cold-pressed sunflower oil comparable with butylated hydroxyanisole (BHA) and butylated hydroxytoluene (BHT), which were evaluated using peroxide and thiobarbituric acid values. The antioxidant activity of the essential oil was additionally validated using DPPH radical scavenging $(0.0016 \pm 0.0885 \mathrm{mg} / \mathrm{mL})$, and $\beta$-carotene-linoleic acid bleaching assays. Also, the amounts of total phenol components $(0.0053 \pm 0.0023 \mathrm{mg} \mathrm{GAE} / \mathrm{g})$ were determined.
\end{abstract}

Keywords: essential oil; wild parsnip; Pastinaca sativa L. ssp. sylvestris [Mill.] Rouy and Camus; antioxidant activity

\section{Introduction}

Lipid oxidation and the decomposition of oxidation products represent the main deterioration processes which result in decreasing shelf-life, nutritional value and the generation of off odours and off flavours, altering the texture and colour of food products [1]. These quality deteriorations cause the rejection of affected foods by consumers. To reduce the rate of auto-oxidation, several techniques can be adopted, such as the prevention of oxygen access by using suitable packaging materials, storage of food products on lower temperatures or inactivation of enzymes catalysing oxidation [2]. However, these techniques are not always practical or economical from the nutritional and technological points of view [3]. Under these circumstances, the usage of food antioxidants (BHA, BHT, and propyl gallate), capable of inhibiting or delaying the lipid oxidation, is highly desirable.

Due to the potential adverse health effects of synthetic antioxidants [4-6], and as a result of consumer requests to reduce the usage of synthetic additives over the past four decades, hundreds of essential oils (EOs) have been evaluated to identify suitable and safe sources of natural antioxidants. Different studies have demonstrated EOs' potential as natural preservatives agents for food [7-9] and as possible substitutes for synthetic antioxidants $[3,10]$ in specific areas of food processing where their 
use is not in contrast with their aroma. Despite this potential as food antioxidants, due to their excellent antioxidant properties, EOs have limited applications as food additives. In the European Union, only rosemary extracts were labelled as food additives (antioxidants) by the European Commission (EC) and assigned the number E392 according to Directives 2010/67/EU and 2010/69/EU [11,12] repealed by Regulation (EC) 231/2012 and 1333/2008 [13,14].

Even though a large number of EOs have been studied over the last decades, some of them have not been sufficiently considered or remain unexplored. Wild parsnip, an herbaceous biennial, within the Apiaceae (Umbelliferae) family, is one of the less studied species regarding its EO bioactive properties. Four subspecies of wild parsnip are found across Eurasia. Pastinaca sativa L. ssp. sativa is widely cultivated throughout the Northern Hemisphere; ssp. urens [Req. ex Godron] Celak. and ssp. sylvestris [Mill.] Rouy and Camus are distributed in several countries, including France, Georgia, Italy, Romania, the Russian Federation, Switzerland, and Ukraine; and ssp. latifolia [Duby] DC., is endemic to Corsica $[15,16]$. The EO isolate from wild parsnip seeds is dominated by the aliphatic esters octyl acetate and octyl butyrate [17], while the root EO contains myristicin and terpinolene as principal components [18]. To the best of the authors' knowledge, no study investigating the antioxidant proprieties of $P$. sylvestris $\mathrm{EO}$ has been reported before.

Our research aims are to determine the chemical composition and the antioxidant properties of the EO of P. sylvestris grown wild in Romania in order to identify new sources of natural antioxidants with applicability in the food industry.

\section{Results and Discussion}

\subsection{Essential Oil Composition}

The EO was extracted from $P$. sylvestris seeds with a yield of $0.41 \%(w / v)$. The results obtained by GC-MS analysis are presented in Table 1. Thirty-two compounds were identified, representing $99.68 \%$ of the total EO. Octyl acetate $(78.49 \%)$, octyl hexanoate $(6.68 \%)$, hexyl butyrate $(2.71 \%)$ and octyl butyrate $(1.82 \%)$ were the main components of analysed EO. The literature is limited with regard to the chemical composition of the wild parsnip (P. sativa) EO. Carroll et al. reported that aliphatic esters, octyl acetate and octyl butyrate occur as the major components of EOs of the mature seeds of wild parsnip [17]. The presences of these aliphatic esters, octyl butyrate (79.5\%) and octyl acetate (0.3\%), was also recorded in the Turkish Pastinaca sativa subsp. urens EO [18]. According to Carroll et al., the production of octyl acetate and octyl butyrate in mature fruits of wild parsnip does not share a common genetic regulation. The two are positively correlated phenotypically [17]. This correlation appears to be due entirely to environmental effects, as there is no genetic correlation, in spite of their origin from a common biosynthetic pathway [19].

Table 1. The chemical composition of the EO extracted from P. sylvestris seeds.

\begin{tabular}{clll}
\hline No & Common Name & RI $^{\mathbf{a}}$ & $\mathbf{\%}$ \\
\hline 1 & iso-propyl iso-valerate & 884 & tr. \\
2 & Nonane & 890 & tr. \\
3 & Santolina triene & 891 & tr. \\
4 & Alpha-pinene & 919 & 0.24 \\
5 & 3-hexyl hydroperoxide & 926 & 0.11 \\
6 & 2-hexyl hydroperoxide & 934 & 0.14 \\
7 & Alpha-phellandrene & 954 & 0.22 \\
8 & Beta-pinene & 959 & 0.87 \\
9 & Furan, 2-pentyl & 970 & 0.13 \\
10 & Octanal & 982 & 0.82 \\
11 & Hexyl acetate & 991 & 0.18 \\
12 & Para-cymene & 1006 & 0.06 \\
\hline
\end{tabular}


Table 1. Cont.

\begin{tabular}{cllll}
\hline No & Common Name & RI $^{\mathbf{a}}$ & $\mathbf{\%}$ \\
\hline 13 & Limonene & 1011 & 0.13 \\
14 & Eucalyptol & 1014 & 0.25 \\
15 & Butyl 2-methylbutyrate & 1022 & 0.14 \\
16 & n-octanol & 1054 & 0.57 \\
17 & n-nonanal & 1092 & 0.27 \\
18 & Hexyl isobutyrate & 1140 & 0.26 \\
19 & Ethylidenecyclohexane & 1146 & 0.17 \\
20 & Hexyl butyrate & 1190 & 2.71 \\
21 & Decanal & 1207 & 0.56 \\
22 & Octyl acetate & 1217 & 78.49 \\
23 & Hexyl 2-methylbutyrate & 1240 & 0.66 \\
24 & n-hexyl iso-valerate & 1247 & 0.16 \\
25 & Thymol & 1300 & 0.07 \\
26 & Octyl butyrate & 1407 & 1.82 \\
27 & Decanol acetate & 1428 & 0.81 \\
28 & Caryophyllene & 1439 & 0.74 \\
29 & trans-alpha-Bergamotene & 1453 & 0.94 \\
30 & beta-Cubebene & 1502 & 0.56 \\
31 & Octyl hexanoate & 1601 & 6.68 \\
32 & Chamazulene & 1735 & 0.92 \\
& & Total & 99.68 \\
\hline
\end{tabular}

a the retention index (RI) was calculated using a homologous series of $n$-alkanes $C_{8}-C_{20}$; tr. (trace): $<0.05$.

\subsection{Antioxidant Activity}

Peroxide value is one of the most common tests used to estimate the primary oxidation of oils and fats and measure the concentration of peroxides and hydroperoxides formed in this stage of lipid oxidation [20]. The evolution of the peroxide value during the storage period ( 20 days) for the control and treated samples are shown in Table 2. The results of ANOVA analysis applied on peroxide values show highly significant $(p<0.001)$ main effects (antioxidant and time) but also a highly significant $(p<0.001)$ interaction effect. The differences at each testing period, according to the Duncan test, are also shown in Table 2. The best results are obtained by BHT and the sample treated with $300 \mathrm{mg} / \mathrm{L}$ EO. The changing position (crossing effect) can partly explain the high significance of the interaction effect. For example, after four days of storage, the sample treated with $300 \mathrm{mg} / \mathrm{L} \mathrm{EO}$ has a significantly $(p<0.001)$ lower peroxide level than BHT, but after 16 days, BHT has a substantially $(p<0.001)$ lower peroxide level than EO (300 mg/L). In this situation, even if it is not clear which one of the two samples perform better, at least we may conclude that the $\mathrm{EO}(300 \mathrm{mg} / \mathrm{L})$ has comparable results with BHT. Regarding the BHA, the conclusion is more clear-cut because the sample with EO $(300 \mathrm{mg} / \mathrm{L})$ performs significantly better $(p<0.01)$ at three measurement periods, the other three cases show no significant differences.

Table 2. Inhibitory effect of the P. sylvestris seeds essential oil on the primary oxidation of sunflower oil measured by peroxide value method (meq of oxygen $\mathrm{kg}^{-1}$ ).

\begin{tabular}{ccccccc}
\hline Treatment & 0 Days & 4 Days & 8 Days & 12 Days & 16 Days & 20 Days \\
\hline Control & $1.71^{\mathrm{a}}( \pm 0.15)$ & $4^{\mathrm{a}}( \pm 0.45)$ & $7.25^{\mathrm{a}}( \pm 0.25)$ & $19.25^{\mathrm{a}}( \pm 0.54)$ & $26.07^{\mathrm{a}}( \pm 0.3)$ & $41.58^{\mathrm{a}}( \pm 0.74)$ \\
BHT & $\mathbf{1 . 6 1}^{\mathrm{a}}( \pm \mathbf{0 . 1 5})$ & $2.8^{\mathrm{bc}}( \pm 0.08)$ & $4.29^{\mathrm{de}}( \pm 0.3)$ & $\mathbf{6 . 4 3}^{\mathrm{d}}( \pm \mathbf{0 . 4 6})$ & $\mathbf{9 . 5 3}^{\mathrm{d}}( \pm \mathbf{0 . 2 8})$ & $12.31^{\mathrm{d}}( \pm 0.37)$ \\
BHA & $1.68^{\mathrm{a}}( \pm 0.14)$ & $2.9^{\mathrm{b}}( \pm 0.02)$ & $4.97^{\mathrm{bc}}( \pm 0.14)$ & $6.86^{\mathrm{cd}( \pm 0.09)}$ & $10.63^{\mathrm{c}}( \pm 0.23)$ & $14.58^{\mathrm{bc}}( \pm 0.28)$ \\
EO $(100 \mathrm{mg} / \mathrm{L})$ & $1.74^{\mathrm{a}}( \pm 0.09)$ & $4.01^{\mathrm{a}}( \pm 0.17)$ & $5.2^{\mathrm{b}}( \pm 0.14)$ & $8.02^{\mathrm{b}}( \pm 0.2)$ & $13.06^{\mathrm{b}}( \pm 0.06)$ & $15.09^{\mathrm{b}}( \pm 0.06)$ \\
EO $(200 \mathrm{mg} / \mathrm{L})$ & $1.72^{\mathrm{a}}( \pm 0.08)$ & $2.34^{\mathrm{cd}}( \pm 0.19)$ & $4.56^{\mathrm{cd}}( \pm 0.15)$ & $7.39^{\mathrm{bc}}( \pm 0.17)$ & $11.11^{\mathrm{c}}( \pm 0.32)$ & $13.86^{\mathrm{c}}( \pm 0.01)$ \\
EO $(300 \mathrm{mg} / \mathrm{L})$ & $1.7^{\mathrm{a}}( \pm 0.06)$ & $\mathbf{1 . 8 2}^{\mathrm{d}} \mathbf{( \pm \mathbf { 0 . 0 2 } )}$ & $\mathbf{4 . 0 4}^{\mathrm{e}}( \pm \mathbf{0 . 0 8})$ & $6.93^{\mathrm{cd}}( \pm 0.06)$ & $10.82^{\mathrm{c}}( \pm 0.13)$ & $\mathbf{1 1 . 9 1}^{\mathrm{d}}( \pm \mathbf{0 . 2 3})$ \\
\hline
\end{tabular}

a, b, c, d, e_-values with different superscript are significantly different $(p<0.01)$ according to Duncan test; lowest values are marked; bolded in grey cells; each value is the Mean \pm SD. 
The synthetic results of linear regression analysis are shown in Table 3. Even if not statistically significant, the control is the only equation with a negative intercept (not shown in Table 3). This interpretation problem can be solved by estimating a quadratic equation that would represent a better fit (R-sq. = 0.99). However, for comparability purposes, the linear equation has been used. As can be seen in the linear estimation, slopes are not significantly different between the five samples, but all of them have slopes that are significantly different from the control $(p<0.01)$. This fact can be explained by the quadratic tendency of peroxide values in the control group. This quadratic tendency also represents a second important explanation for the interaction effect identified in the ANOVA analysis.

Table 3. Linear regression analysis of peroxide values with incubation period as independent variable.

\begin{tabular}{cccccccc}
\hline \multirow{2}{*}{ Peroxide Value (days) } & Control & BHT & BHA & \multicolumn{3}{c}{ EO } \\
\cline { 6 - 7 } & & & & & $\mathbf{1 0 0} \mathbf{~} \mathbf{g} / \mathbf{L}$ & $\mathbf{2 0 0} \mathbf{~} \mathbf{~ g} / \mathbf{L}$ & $\mathbf{3 0 0} \mathbf{~} \mathbf{g} / \mathbf{L}$ \\
\hline R-sq. & 0.93 & 0.97 & 0.96 & 0.96 & 0.96 & 0.95 \\
Slope & $1.97^{\mathrm{a}}$ & $0.54^{\mathrm{b}}$ & $0.64^{\mathrm{b}}$ & $0.69^{\mathrm{b}}$ & $0.64^{\mathrm{b}}$ & $0.58^{\mathrm{b}}$ \\
Std. error & 0.14 & 0.03 & 0.03 & 0.03 & 0.03 & 0.03 \\
\hline
\end{tabular}

a, b_slopes with different superscript are significantly different $(p<0.01)$ in multiple regression equation; R-squared, slope and standard error of slope are shown for each single regression equation.

The thiobarbituric acid value (TBA) value is an index of lipid oxidation, widely used as an indicator for the evaluation of the degree of secondary lipid oxidation [21,22]. The TBA values of the control and treated samples during the 20 days of storage are shown in Table 4 . The results of the general ANOVA model applied to the TBA value are very similar with those for peroxide values: highly significant $(p<0.001)$ main effects (antioxidant and time) and also a highly significant $(p<0.001)$ interaction effect. The differences at each testing period, according to the Duncan test, are also shown in Table 4 . The best results are obtained by the EO $(200 \mathrm{mg} / \mathrm{L})$ for the zero-days testing period and BHT in the rest. Even if the BHT is relatively stable in the first position regarding the antioxidant efficiency, the changing of the position between the other samples at different time intervals is worth noticing. A promising result from our perspective is that TBA values for the $\mathrm{EO}(300 \mathrm{mg} / \mathrm{L})$ are slightly better than those of BHA. TBA values for BHA are lower in the case of the zero-days and 16-days measurements, with a statistically significant difference $(p<0.01)$. However, the EO $(300 \mathrm{mg} / \mathrm{L})$ performs significantly better $(p<0.01)$ in three cases: at the $4 \mathrm{~s}, 12$ and 20 day measurements.

Table 4. Inhibitory effect of the P. sylvestris seed essential oil on the secondary oxidation of sunflower oil measured by thiobarbituric acid value (TBA) value ( $\mu$ g malondialdehyde $\mathrm{g}^{-1}$ ).

\begin{tabular}{|c|c|c|c|c|c|c|}
\hline Treatment & 0 Days & 4 Days & 8 Days & 12 Days & 16 Days & 20 Days \\
\hline ВHT & $1.84^{\mathrm{e}}( \pm 0.03)$ & $6.76^{c}( \pm 0.14)$ & $5.93^{d}( \pm 0.09)$ & $6.93^{f}( \pm 0.1)$ & $9.73^{d}( \pm 0.04)$ & $17.2^{\mathrm{e}}( \pm 0.19)$ \\
\hline EO (100 mg/L) & $3.00^{\mathrm{a}}( \pm 0.05)$ & $10.39^{a}( \pm 0.32)$ & $8.75^{\mathrm{b}}( \pm 0.18)$ & $10.45^{\mathrm{e}}( \pm 0.3)$ & $16.59^{b}( \pm 0.17)$ & $22.57^{\mathrm{b}}( \pm 0.13)$ \\
\hline EO $(200 \mathrm{mg} / \mathrm{L})$ & $1.66^{f}( \pm 0.06)$ & $8.62^{b}( \pm 0.25)$ & $8.63^{b}( \pm 0.35)$ & $11.63^{c}( \pm 0.21)$ & $14.6^{c}( \pm 0.17)$ & $18.31^{\mathrm{d}}( \pm 0.21)$ \\
\hline EO (300 mg/L) & $2.48^{\mathrm{c}}( \pm 0.04)$ & $6.9^{\mathrm{c}}( \pm 0.07)$ & $7.73^{c}( \pm 0.12)$ & $11.09^{\mathrm{d}}( \pm 0.22)$ & $16.0^{\mathrm{b}}( \pm 0.09)$ & $17.25^{\mathrm{e}}( \pm 0.13)$ \\
\hline
\end{tabular}

The synthetic results of linear regression analysis are shown in Table 5. The control is again the only equation with a negative intercept (not shown in Table 5). A quadratic equation for the control would lead to R-sq. $=0.99$. In the linear estimation, the slope of the control is much higher and significantly different from the five tested antioxidants $(p<0.01)$. 
Table 5. Linear regression analysis of TBA value with storage period as independent variable.

\begin{tabular}{cccccccc}
\hline \multirow{2}{*}{ TBA Value (days) } & Control & \multirow{2}{*}{ BHT } & BHA & \multicolumn{3}{c}{ EO } \\
\cline { 5 - 7 } & & & & $\mathbf{1 0 0} \mathbf{~} \mathbf{g} / \mathbf{L}$ & $\mathbf{2 0 0} \mathbf{~} \mathbf{g} / \mathbf{L}$ & $\mathbf{3 0 0} \mathbf{~} \mathbf{g} / \mathbf{L}$ \\
\hline R-sq. & 0.88 & 0.81 & 0.92 & 0.87 & 0.94 & 0.97 \\
Slope & $2.90^{\mathrm{a}}$ & $0.62^{\mathrm{b}}$ & $0.79^{\mathrm{b}}$ & $0.84^{\mathrm{b}}$ & $0.74^{\mathrm{b}}$ & $0.75^{\mathrm{b}}$ \\
Std. error & 0.27 & 0.07 & 0.06 & 0.08 & 0.05 & 0.03 \\
\hline
\end{tabular}

a, b_Slopes with different superscript are significantly different $(p<0.01)$ in multiple regression equation; R-squared, slope and standard error of slope are shown for each single regression equation.

The 1,1-diphenyl-2-picrylhydrazyl (DPPH) radical is a stable radical with a maximum absorbance at $517 \mathrm{~nm}$ that can readily undergo reduction by an antioxidant [23]. When a solution of DPPH is mixed with that of a substance that can donate a hydrogen atom, then this gives rise to the reduced form with the loss of this violet colour [24]. Table 6 shows the DPPH free radical scavenging activity of the $\mathrm{PEO}$ and synthetic additives used as positive controls. Lower $\mathrm{IC}_{50}$ value means higher antioxidant activity. The $\mathrm{EO}\left(\mathrm{IC}_{50}=0.0016 \pm 0.0885 \mathrm{mg} / \mathrm{mL}\right)$ exhibited higher scavenging ability on DPPH radicals than BHA and BHT.

$\beta$-carotene-linoleic acid bleaching assay is based on the loss of the yellow colour of $\beta$-carotene when reacting with the radicals produced by linoleic acid oxidation in an emulsion. The rate of $\beta$-carotene bleaching can be slowed down in the presence of antioxidants [25]. The relative antioxidative activity (RAA) of the EO was calculated using the formula: RAA $=A_{E O} / A_{B H T}$, where $A_{B H T}$ is the absorbance of the BHT (the positive control used) and $\mathrm{A}_{\mathrm{EO}}$ is the absorbance of the EO. The calculated RAA of the analysed EO is $97.646 \% \pm 0.006 \%$ (Table 6). Based on the data known to us, the antioxidant activity of the EO from P. sylvestris seed has not been reported in other studies, which does not allow a comparative analysis of the results obtained.

Table 6. Total phenolic content, $\beta$-carotene bleaching and DPPH radical scavenging activities of the EO extracted from P. sylvestris seeds.

\begin{tabular}{|c|c|c|c|}
\hline Parameter & EO & BHA $^{\text {a }}$ & $\mathrm{BHT}^{\mathrm{b}}$ \\
\hline $\mathrm{DPPH}, \mathrm{IC}_{50}(\mathrm{mg} / \mathrm{mL})$ & $0.0016 \pm 0.0885$ & $0.0070 \pm 0.0003$ & $0.0091 \pm 0.0003$ \\
\hline$\beta$-carotene bleaching $\left(\right.$ RAAs) ${ }^{c}(\%)$ & $97.646 \pm 0.006$ & $\mathrm{Nd}^{\mathrm{e}}$ & 100 \\
\hline Total Phenolic Content, (mg GAE/g) ${ }^{\mathrm{d}}$ & $0.0053 \pm 0.0023$ & $\mathrm{Nd}^{\mathrm{e}}$ & $\mathrm{Nd}^{\mathrm{e}}$ \\
\hline
\end{tabular}

The antioxidant activity of EOs is related to their chemical composition [26]. Generally, the antioxidant properties of EOs are attributed to their main compounds [27]. In our study, the aliphatic esters (Table 1) dominate the chemical composition of the tested EO but possess lower antioxidant effectiveness [28]. Octyl acetate was previously reported to exhibit a moderate [28] to weak antioxidant effect [29], while octyl butyrate did not show any antioxidant activity [29]. On the other hand, between the minor components, we find several compounds, including eucalyptol, beta-pinene, para-cymene, caryophyllene, and limonene, recognized for their antioxidant properties [28]. Based on this information, the antioxidant activity of the EO isolated from P. sylvestris seeds probably depends partially on the synergism and additive effects between components.

\subsection{Total Phenols Content}

Previous studies reported the relationship between the presence of phenols and antioxidant potential of the EOs [30-32]. The antioxidant activity of the phenols, organic compounds that contain a hydroxyl group bound directly to the aromatic ring, is mainly due to their ability to donate their phenolic hydrogen to lipid free-radicals [1,25]. The analysed EO records a low phenol content 
$(0.0053 \pm 0.0023 \mathrm{mg} \mathrm{GAE} / \mathrm{g})$ but exhibited high antioxidant activity comparable with BHA and BHT, the synthetic antioxidants used as positive controls. Teixeira et al. also reported high antioxidant activity for the Mentha pulegium EO of Portuguese origin that records a low phenol content [33]. The same tendency was reported for several plant extracts such as Malva blanca, Schinus molle, Curcuma longa, Cyclanthera pedata, and Opuntia soehrensii, which, despite showing a low content of total phenolics, exhibited a high antioxidant activity [34].

These results suggest that other compounds of different polarities, probably released through hydrolysis and other cleavage processes, may also contribute to the recorded antioxidant activity [23,34]. Moreover, heat- and water-induced chemical reactions can also change the activity of a complex extraction system consisting of numerous compounds with different chemical and physical properties [23].

\section{Materials and Methods}

\subsection{Chemicals}

All reagents used were of analytical grade. Thiobarbituric acid (TBA), chloroform, diphenylpicrylhydrazyl radical (DPPH), Folin and Ciocalteu's phenol reagent $(2 \mathrm{~N})$, butylated hydroxyanisole (BHA), butylated hydroxytoluene (BHT) and $\mathrm{C}_{8}-\mathrm{C}_{20}$ alkane standard mixture were purchased from Sigma-Aldrich (Germany).

\subsection{Essential Oil Extraction}

Mature seeds of P. sylvestris were harvested from the Ludestii de Jos, Hunedoara County (Coordinates: $45^{\circ} 43^{\prime} 5^{\prime \prime} \mathrm{N} 23^{\circ} 10^{\prime} 21^{\prime \prime} \mathrm{E}$ ) in August 2018. After the identification, a voucher specimen (VSNH.BUASTM-122) was deposited in the Herbarium of the Faculty of Agronomy, Banat's University of Agricultural Sciences and Veterinary Medicine "King Michael I of Romania" from Timisoara. The seeds were dried under natural conditions (protected from sunlight and natural ventilated). The P. sylvestris essential oil (PEO) was obtained through steam distillation, according to the method previously described [35]. After decantation, the $\mathrm{EO}$ was dried over anhydrous sodium sulphate (Sigma, Germany) and stored in sealed amber vials at $-18^{\circ} \mathrm{C}$.

\subsection{Gas Chromatography-Mass Spectrometry Analysis}

The EO sample was diluted in hexane 1:1000 and injected in an HP6890 Gas-Chromatograph coupled with HP5973 Mass Spectrometer. One $\mu \mathrm{L}$ of the sample was injected in splitless mode on a capillary column, Br-5MS, 5\% Phenyl-arylene-95\% Dimethylpolysiloxane, $30 \mathrm{~m}$ length, $0.25 \mathrm{~mm}$ internal diameter, $0.25 \mu \mathrm{m}$ film thickness (Bruker). The gas chromatograph's oven temperature programme was in a range of 50 to $300{ }^{\circ} \mathrm{C}$ with $6{ }^{\circ} \mathrm{C} /$ minute, with a final hold of $5 \mathrm{~min}$ and a solvent delay of $3 \mathrm{~min}$. The mass spectrometer source was set at $230^{\circ} \mathrm{C}$, MS Quad was set at $150{ }^{\circ} \mathrm{C}$, and the ionization energy was $70 \mathrm{eV}$. The gas helium flow rate was $1 \mathrm{~mL} / \mathrm{min}$. The mass of the compounds scanned was between 50 and $550 \mathrm{amu}$. The compounds present in the sample were evaluated based on their spectra compared to the mass spectra from the NIST0.2 library (USA National Institute of Science and Technology software). Area percentage was calculated, and a semi-qualitative analysis was made based on their retention times by calculating their retention indices (RIs), based on a calibration curve with a $\mathrm{C}_{8}-\mathrm{C}_{20}$ alkane standard mixture (Sigma-Aldrich, St. Louis, MO, USA). A comparison of their calculated RIs with Adams indices from literature data was made [36].

\subsection{Antioxidant Activity}

\subsubsection{Sample Preparation}

To assess the antioxidant activities of PEO, cold-pressed sunflower oil acquired from the local market, with an initial peroxide value $1.8 \mathrm{meq} \mathrm{kg}{ }^{-1}$, was used in our research. The antioxidant 
activity of PEO was tested by comparing the activity of two synthetic antioxidants such as BHA and BHT by peroxide and thiobarbituric acid values. The calculated quantities of EO, 100, 200 and $300 \mathrm{mg} / \mathrm{L}$, respectively, were added to $10 \mathrm{~mL}$ of cold-pressed sunflower oil. Separately, $200 \mathrm{mg} / \mathrm{L}$ of each antioxidant, the maximum amount of BHT and BHA in fats and oils for the professional manufacturer of heat-treated foodstuffs according to Directive 2006/52/EC [37], were added also to $10 \mathrm{~mL}$ cold-pressed sunflower oil. Meanwhile, $10 \mathrm{~mL}$ of cold-pressed sunflower oil without any additive was used as a control sample.

\subsubsection{Peroxide Value}

The peroxide values (meq of oxygen $\mathrm{kg}^{-1}$ ) were determined by the potentiometric method according to ISO 27107:2010 [38] every four days. All tests were replicated three times.

\subsubsection{Thiobarbituric acid value (TBA)}

The test was performed according to the methods previously described [23] with minor modifications. Two g of each of sample was prepared as described according to the peroxide value method and with $5 \mathrm{~mL}$ of benzene and $4 \mathrm{~mL}$ of thiobarbituric acid $(0.67 \%$ aqueous) were added. The mixtures thus prepared were shaken for one hour using a mechanical stirrer. After one hour, the supernatant was taken and placed in a boiling water bath for $45 \mathrm{~min}$. The absorbance of the supernatant was measured after cooling at $540 \mathrm{~nm}$ with Specord 210 Analytik Jena spectrophotometer. All tests were replicated three times.

\subsubsection{Scavenging Effect on 1,1-diphenyl-2-picrylhydrazyl Radical (DPPH)}

The EO was analysed regarding free radical scavenging activity using a Brand-Williams' adapted method [39,40]. Briefly, $100 \mu \mathrm{L}$ of samples at different concentrations $(1.5,0.75,0.375$, $0.187,0.093 \mathrm{mg} / \mathrm{mL}$ ), diluted in methanol, were placed in a 96-well microplate, and then $10 \mu \mathrm{L}$ of DPPH $(1 \mathrm{mg} / \mathrm{mL})$ solution was added. After incubation for $30 \mathrm{~min}$ in the dark at room temperature, the absorbance was measured at $515 \mathrm{~nm}$ using a spectrophotometer Tecan i-control, 1.10.4.0 infinite 200Pro. BHT and BHA were used as the positive controls, and methanol served as the negative control. An inhibition percentage of the DPPH free radical was calculated after the formula: $\mathrm{I} \%=\left(\mathrm{A}_{\text {blank }}-\mathrm{A}_{\text {sample }} / \mathrm{A}_{\text {blank }}\right) \times 100$, where $\mathrm{A}_{\text {blank }}$ expresses the absorbance of the control, and $\mathrm{A}_{\text {sample }}$ expresses the absorbance of the test sample.

IC50 was obtained using the BioDataFit 1.02 software (Chang Broscience Inc, Castro Valley, CA, USA). All tests were replicated three times.

\subsection{5. $\beta$-Carotene Bleaching Assay}

Oxidation scavenging activity of EO sample was performed using the $\beta$-carotene bleaching method [25]. Briefly, a stock solution of the $\beta$-carotene-linoleic acid mixture was prepared: $0.5 \mathrm{mg}$ $\beta$-carotene was dissolved in $1 \mathrm{~mL}$ of chloroform, then, $25 \mu \mathrm{l}$ linoleic acid and $200 \mathrm{mg}$ Tween 40 were added. Chloroform was evaporated entirely by using a vacuum evaporator. Later, $100 \mathrm{~mL}$ of distilled water saturated with oxygen was added and shaken vigorously for 2-3 min until an emulsion was formed. Then, $2.5 \mathrm{~mL}$ of the solution was transferred into the test tubes with $350 \mu \mathrm{l}$ of the EO sample $(2 \mathrm{~g} / \mathrm{L}$ concentration). The emulsion system was incubated for up to $48 \mathrm{~h}$ at room temperature. The same procedure was repeated for the synthetic antioxidant (BHT), used as positive controls, and a blank probe containing only $350 \mu \mathrm{l}$ of ethanol. After the incubation period, the absorbances of the mixtures were measured at $490 \mathrm{~nm}$. All tests were replicated three times. The antioxidative capacities of the EO sample were compared with those of blank and BHT. 


\subsubsection{Determination of Total Phenols}

The total phenolic content (TPC) of the EO sample was performed with an adapted Folin-Ciocalteu method, as previously described [40,41] with minor modifications. Briefly, $15 \mathrm{mg}$ of the EO sample was weighted and mixed with $1 \mathrm{~mL}$ methanol. The mixture was vortexed and combined in a 1:5 ratio sample with Folin-Ciocalteu reagent (diluted 1:10 in distilled water to obtain a $0.25 \mathrm{~N}$ concentration) and left for five minutes in the dark at room temperature; after this, an equal volume of $7.5 \%$ sodium carbonate solution with Folin-Ciocalteu reagent was added, mixed, and left for $1 \mathrm{~h}$ in the dark at room temperature. The samples were plated in triplicate in 96-well plates, and the absorbance was measured at $725 \mathrm{~nm}$ with a spectrophotometer Tecan i-control, 1.10.4.0 infinite 200Pro. TPC was expressed in gallic acid equivalents (mg GAE/g sample) calculated after a propyl gallate calibration curve with concentrations between $0.375 \mathrm{mg} / \mathrm{mL}$ to $0.732 \mu \mathrm{g} / \mathrm{mL}$.

\subsection{Statistical Analysis}

To preserve the comparability of the results, the statistical methodology used in our research was mainly in line with the existing research in the field [42]. To compare the antioxidant activity of PEO with the control sample and the other two standard antioxidants, in the first stage of the analysis, the peroxide and TBA values were analysed using two-way ANOVA with main and interaction effects. The levels of the first factor were represented by control, BHT, BHA, and three concentrations of PEO $(100,200$, and $300 \mathrm{mg} / \mathrm{L})$. The second factor (ordered) was represented by the incubation period at six levels expressed in days. The scope of this stage was, in the first place, to test if there were significant overall differences between control, BHT, BHA, and three concentrations of PEO regarding their antioxidant activity. Secondly, overall significant differences between the levels of the incubation period were also tested at this stage. Lastly, the interaction effect between antioxidants and the incubation period was tested.

Because the interaction effect proved to be significant $(p<0.001)$, a more thorough analysis was done in the second stage of our research, to reveal and better describe the type of interaction. More specifically, pairwise comparisons were realized between all the levels of the first factor at each level of the incubation period using the Duncan test [42].

The last stage of our research was focused on the antioxidant dynamic during the incubation period. Considering the incubation period as a covariate, this analysis was performed by using simple and multiple regression analysis. The single regression analysis was used for each antioxidant and the control to test the tendency of antioxidant activity in time (i.e., slope). Differences in slope were tested in the framework of multiple regression with dummy variables, including all antioxidants and the control in one equation. Both linear and quadratic time effects were tested. Each statistical method was applied separately for peroxide and TBA values. Statistical analysis of the data was realized mainly by using R 3.5.3 (Base and Agricolae packages).

\section{Conclusions}

In summary, the main components in the PEO were octyl acetate $(78.49 \%)$, octyl hexanoate $(6.68 \%)$, hexyl butyrate $(2.71 \%)$ and octyl butyrate $(1.82 \%)$. PEO recorded significant activity for the inhibition of primary and secondary oxidation products. The antioxidant performance of PEO proved to be statistically significant $(p<0.01)$ in specific situations, such as high concentrations $(300 \mathrm{mg} / \mathrm{L})$ and long incubation periods (20 days), but is not limited to these conditions. Moreover, the antioxidant activity of the PEO was also confirmed by DPPH radical scavenging and $\beta$-carotene-linoleic acid bleaching assays. However, the low amounts of total phenol components determined in the analysed EO suggest that other compounds of different polarities, probably released during the cleavage process, may also contribute to the recorded antioxidant activity. Future studies should evaluate the relationship between antioxidant activity and chemical composition of EOs. 
In conclusion, the results suggest that the PEO may represent an alternative to the usage of synthetic antioxidants to extend the shelf life of foods containing oils and fats.

Author Contributions: C.J. and D.S. designed the experiments, analysed the data and wrote the paper; A.T.L.-G. performed the GC-MS analysis; A.T.L.-G. and I.C. performed the antioxidant analysis; I.G. performed the statistical analysis. All authors have read and agreed to the published version of the manuscript.

Funding: This research study was supported by the project financed by the Ministry of Research and Innovation (MCI) through Program 1-Development of the national research and development system, Subprogram 1.2-Institutional performance, Institutional development projects-Projects to fund excellence in RDI, code 35PFE/2018.

Conflicts of Interest: The authors declare no conflict of interest.

\section{References}

1. Shahidi, F.; Ambigaipalan, P. Phenolics and polyphenolics in foods, beverages and spices: Antioxidant activity and health effects-A review. J. Funct. Foods 2015, 18, 820-897. [CrossRef]

2. Dorman, H.; Peltoketo, A.; Hiltunen, R.; Tikkanen, M. Characterisation of the antioxidant properties of de-odourised aqueous extracts from selected Lamiaceae herbs. Food Chem. 2003, 83, 255-262. [CrossRef]

3. Viuda-Martos, M.; Ruiz Navajas, Y.; Sánchez Zapata, E.; Fernández-López, J.; Pérez-Álvarez, J.A. Antioxidant activity of essential oils of five spice plants widely used in a Mediterranean diet. Flavour Fragr. J. 2010, 25, 13-19. [CrossRef]

4. de Gonzalez, M.N.; Hafley, B.; Boleman, R.; Miller, R.; Rhee, K.; Keeton, J. Antioxidant properties of plum concentrates and powder in precooked roast beef to reduce lipid oxidation. Meat Sci. 2008, 80, 997-1004. [CrossRef]

5. Biparva, P.; Ehsani, M.; Hadjmohammadi, M.R. Dispersive liquid-liquid microextraction using extraction solvents lighter than water combined with high performance liquid chromatography for determination of synthetic antioxidants in fruit juice samples. J. Food Compos. Anal. 2012, 27, 87-94. [CrossRef]

6. Rodil, R.; Quintana, J.B.; Basaglia, G.; Pietrogrande, M.C.; Cela, R. Determination of synthetic phenolic antioxidants and their metabolites in water samples by downscaled solid-phase extraction, silylation and gas chromatography-mass spectrometry. J. Chromatogr. A 2010, 1217, 6428-6435. [CrossRef]

7. Jianu, C.; Golet, I.; Misca, C.; Jianu, A.M.; Pop, G.; Gruia, A.T. Antimicrobial properties and chemical composition of essential oils isolated from six medicinal plants grown in Romania against foodborne pathogens. Rev. Chim. 2016, 67, 1056-1061.

8. Donsi, F.; Annunziata, M.; Sessa, M.; Ferrari, G. Nanoencapsulation of essential oils to enhance their antimicrobial activity in foods. LWT-Food Sci. Technol. 2011, 44, 1908-1914. [CrossRef]

9. Gutierrez, J.; Barry-Ryan, C.; Bourke, P. Antimicrobial activity of plant essential oils using food model media: Efficacy, synergistic potential and interactions with food components. Food Microbiol. 2009, 26, 142-150. [CrossRef]

10. Amorati, R.; Foti, M.C.; Valgimigli, L. Antioxidant activity of essential oils. J. Agric. food Chem. 2013, 61, 10835-10847. [CrossRef]

11. European Commission. Commission Directive 2010/67/EU of 20 October 2010 amending Directive 2008/84/EC laying down specific purity criteria on food additives other than colours and sweeteners. Off. J. Eur. Union 2010, 277, 17-26.

12. European Commission. Commission Directive 2010/69/EU of 22 October 2010 amending the Annexes to European Parliament and Council Directive 95/2/EC on food additives other than colours and sweeteners. Off. J. Eur. Union 2010, 279, 22-31.

13. European Commission. Commission Regulation (EU) No 231/2012 of 9 March 2012 laying down specifications for food additives listed in Annexes II and III to Regulation (EC) No 1333/2008 of the European Parliament and of the Council. Off. J. Eur. Union 2012, 83, 1-295.

14. European Commission. Regulation (EC) No 1333/2008 of the European Parliament and of the Council of 16 December 2008 on food additives. Off. J. Eur. Union 2008, 354, 16-33.

15. USDA_ARS Agricultural Research Service, National Plant Germplasm System. 2019; Germplasm Resources Information Network (GRIN-Taxonomy). Available online: https://npgsweb.ars-grin.gov/gringlobal/ taxonomydetail.aspx?id=406686 (accessed on 8 March 2019). 
16. Averill, K.M.; DiTommaso, A.J.W.t. Wild parsnip (Pastinaca sativa): A troublesome species of increasing concern. Weed Technol. 2007, 21, 279-287. [CrossRef]

17. Carroll, M.; Zangerl, A.; Berenbaum, M. Heritability estimates for octyl acetate and octyl butyrate in the mature fruit of the wild parsnip. J. Hered. 2000, 91, 68. [CrossRef]

18. Kurkcuoglu, M.; Baser, K.H.; Vural, M. Composition of the essential oil of Pastinaca sativa L. subsp. urens (Req. ex Godron) Celak. Chem. Nat. Compd. 2006, 42, 114-115. [CrossRef]

19. Mann, J. Secondary Metabolism; Clarendon Press: Oxford, UK, 1987.

20. Elbadrawy, E.; Sello, A. Evaluation of nutritional value and antioxidant activity of tomato peel extracts. Arab. J. Chem. 2016, 9, S1010-S1018. [CrossRef]

21. Jouki, M.; Yazdi, F.T.; Mortazavi, S.A.; Koocheki, A.; Khazaei, N. Effect of quince seed mucilage edible films incorporated with oregano or thyme essential oil on shelf life extension of refrigerated rainbow trout fillets. Int. J. Food Microbiol. 2014, 174, 88-97. [CrossRef]

22. Shadman, S.; Hosseini, S.E.; Langroudi, H.E.; Shabani, S. Evaluation of the effect of a sunflower oil-based nanoemulsion with Zataria multiflora Boiss. essential oil on the physicochemical properties of rainbow trout (Oncorhynchus mykiss) fillets during cold storage. Food Sci. Technol. 2017, 79, 511-517. [CrossRef]

23. Singh, G.; Maurya, S.; De Lampasona, M.; Catalan, C. Chemical constituents, antimicrobial investigations, and antioxidative potentials of Anethum graveolens L. essential oil and acetone extract: Part 52. J. food Sci. 2005, 70, M208-M215. [CrossRef]

24. Molyneux, P. The use of the stable free radical diphenylpicrylhydrazyl (DPPH) for estimating antioxidant activity. Songklanakarin J. Sci. Technol. 2004, 26, 211-219.

25. Oke, F.; Aslim, B.; Ozturk, S.; Altundag, S. Essential oil composition, antimicrobial and antioxidant activities of Satureja cuneifolia Ten. Food Chem. 2009, 112, 874-879. [CrossRef]

26. Barra, A.; Coroneo, V.; Dessi, S.; Cabras, P.; Angioni, A. Chemical variability, antifungal and antioxidant activity of Eucalyptus camaldulensis essential oil from Sardinia. Nat. Prod. Commun. 2010, 5, 1934578X1000500232. [CrossRef]

27. Riahi, L.; Elferchichi, M.; Ghazghazi, H.; Jebali, J.; Ziadi, S.; Aouadhi, C.; Chograni, H.; Zaouali, Y.; Zoghlami, N.; Mliki, A. Phytochemistry, antioxidant and antimicrobial activities of the essential oils of Mentha rotundifolia L. in Tunisia. Ind. Crop. Prod. 2013, 49, 883-889. [CrossRef]

28. Ruberto, G.; Baratta, M.T. Antioxidant activity of selected essential oil components in two lipid model systems. Food Chem. 2000, 69, 167-174. [CrossRef]

29. Maggi, F.; Quassinti, L.; Bramucci, M.; Lupidi, G.; Petrelli, D.; Vitali, L.A.; Papa, F.; Vittori, S. Composition and biological activities of hogweed [Heracleum sphondylium L. subsp. ternatum (Velen.) Brummitt] essential oil and its main components octyl acetate and octyl butyrate. Nat. Prod. Res. 2014, 28, 1354-1363. [CrossRef]

30. Wangensteen, H.; Samuelsen, A.B.; Malterud, K.E. Antioxidant activity in extracts from coriander. Food Chem. 2004, 88, 293-297. [CrossRef]

31. Bakar, M.F.A.; Mohamed, M.; Rahmat, A.; Fry, J. Phytochemicals and antioxidant activity of different parts of bambangan (Mangifera pajang) and tarap (Artocarpus odoratissimus). Food Chem. 2009, 113, 479-483. [CrossRef]

32. Surveswaran, S.; Cai, Y.-Z.; Corke, H.; Sun, M. Systematic evaluation of natural phenolic antioxidants from 133 Indian medicinal plants. Food Chem. 2007, 102, 938-953. [CrossRef]

33. Teixeira, B.; Marques, A.; Ramos, C.; Batista, I.; Serrano, C.; Matos, O.; Neng, N.R.; Nogueira, J.M.; Saraiva, J.A.; Nunes, M.L. European pennyroyal (Mentha pulegium) from Portugal: Chemical composition of essential oil and antioxidant and antimicrobial properties of extracts and essential oil. Ind. Crop. Prod. 2012, 36, 81-87. [CrossRef]

34. Ranilla, L.G.; Kwon, Y.-I.; Apostolidis, E.; Shetty, K. Phenolic compounds, antioxidant activity and in vitro inhibitory potential against key enzymes relevant for hyperglycemia and hypertension of commonly used medicinal plants, herbs and spices in Latin America. Bioresour. Technol. 2010, 101, 4676-4689. [CrossRef] [PubMed]

35. Jianu, C.; Mihail, R.; Muntean, S.G.; Pop, G.; Daliborca, C.V.; Horhat, F.G.; Nitu, R. Composition and antioxidant capacity of essential oils obtained from Thymus vulgaris, Thymus pannonicus and Satureja montana grown in Western Romania. Rev. Chim. 2015, 66, 2157-2160.

36. Adams, R.P. Identification of Essential Oil Components By Gas. Chromatography/Mass Spectrometry; Allured Publishing Corporation: Carol Stream, IL, USA, 2007. 
37. European Commission. Directive 2006/52/EC of the European Parliament and of the Council of 5 July 2006 amending Directive 95/2/EC on food additives other than colours and sweeteners and Directive 94/35/EC on sweeteners for use in foodstuffs. Off. J. Eur. Union 2006, 204, 10-22.

38. ISO. Animal and Vegetable fats and Oils-Determination of Peroxide Value-Potentiometric End-point Determination; International Organization for Standardization: Geneva, Switzerland, 2010; Volume ISO 27107.

39. Brandwilliams, W.; Cuvelier, M.E.; Berset, C. Use of a free-radical method to evaluate antioxidant activity. Food Sci. Technol. 1995, 28, 25-30.

40. Fildan, A.P.; Pet, I.; Stoin, D.; Bujanca, G.; Lukinich-Gruia, A.T.; Jianu, C.; Jianu, A.M.; Radulescu, M.; Tofolean, D.E. Artemisia dracunculus Essential Oil: Chemical composition and antioxidant properties. Rev. de Chim. 2019, 70, 59-62. [CrossRef]

41. Swain, T.; Hillis, W. The phenolic constituents of Prunus domestica. I.-The quantitative analysis of phenolic constituents. J. Sci. Food Agric. 1959, 10, 63-68. [CrossRef]

42. Sebranek, J.G.; Sewalt, V.J.; Robbins, K.L.; Houser, T.A. Comparison of a natural rosemary extract and BHA/BHT for relative antioxidant effectiveness in pork sausage. Meat Sci. 2005, 69, 289-296. [CrossRef]

Sample Availability: The sample of the analysed essential oil is available from the authors.

(C) 2020 by the authors. Licensee MDPI, Basel, Switzerland. This article is an open access article distributed under the terms and conditions of the Creative Commons Attribution (CC BY) license (http://creativecommons.org/licenses/by/4.0/). 